\title{
Long-term safety of bilateral targeted lung denervation in patients with COPD
}

This article was published in the following Dove Press journal:

International Journal of COPD

\author{
Arschang Valipour ${ }^{\prime}$ \\ Sherwin Asadi' \\ Christophe Pison ${ }^{2}$ \\ Marie Jondot ${ }^{2}$ \\ Romain Kessler ${ }^{3}$ \\ Khaled Benneddif ${ }^{3}$ \\ Gaetan Deslee ${ }^{4}$ \\ Margaux Verdier ${ }^{4}$ \\ Dirk-Jan Slebos ${ }^{5}$ \\ Martin Mayse ${ }^{6}$ \\ 'Department of Respiratory and \\ Critical Care Medicine, Ludwig- \\ Boltzmann-Institute for COPD \\ and Respiratory Epidemiology, \\ Otto-Wagner-Spital, Vienna, Austria; \\ ${ }^{2} \mathrm{CHU}$ Grenoble Alpes, Clinique \\ Universitaire de Pneumologie, \\ Université Grenoble Alpes, Grenoble, \\ France; ${ }^{3}$ Service de Pneumologie, \\ Nouvel Hôpital Civil, Université \\ de Strasbourg, Strasbourg, France; \\ ${ }^{4} \mathrm{CHU}$ de Reims, Hôpital Maison \\ Blanche, Service de Pneumologie, \\ INSERM UMRS903, Reims, France; \\ ${ }^{5}$ Department of Pulmonary Diseases, \\ University Medical Center Groningen, \\ University of Groningen, Groningen, \\ the Netherlands; ${ }^{6}$ Nuvaira, Inc., \\ Minneapolis, MN, USA
}

Background: Targeted lung denervation (TLD) is a novel bronchoscopic therapy for COPD which ablates parasympathetic pulmonary nerves running along the outside of the two main bronchi with the intent of inducing permanent bronchodilation. The goal of this study was to evaluate the feasibility and long-term safety of bilateral TLD during a single procedure.

Patients and methods: This prospective, multicenter study evaluated 15 patients with moderate-to-severe COPD (forced expiratory volume in $1 \mathrm{~s}\left[\mathrm{FEV}_{1}\right] 30 \%-60 \%$ ) who underwent bilateral TLD treatment following baseline assessment without bronchodilators. The primary safety end point was freedom from documented and sustained worsening of COPD directly attributable to TLD up to 1 year. Secondary end points included technical feasibility, change in pulmonary function tests, exercise capacity, and health-related quality of life. Follow-up continued up to 3 years for subjects who reconsented for longer-term follow-up.

Results: A total of 15 patients (47\% male, age 63.2 44.0 years) underwent TLD with a total procedure time of $89 \pm 16 \mathrm{~min}$, and the total fluoroscopy time was $2.5 \pm 2.7 \mathrm{~min}$. Primary safety end point of freedom from worsening of COPD was $100 \%$. There were no procedural complications reported. Results of lung function analysis and exercise capacity demonstrated similar beneficial effects of TLD without bronchodilators, when compared with long-acting anticholinergic therapy at 30 days, 180 days, 365 days, 2 years, and 3 years post-TLD. Five of the 12 serious adverse events that were reported through 3 years of follow-up were respiratory related with no events being related to TLD therapy.

Conclusion: TLD delivered to both lungs in a single procedure is feasible and safe with few respiratory-related adverse events through 3 years.

Keywords: COPD, bronchoscopy, radiofrequency ablation, denervation, device

\section{Introduction}

COPD is a global health issue. ${ }^{1-3}$ Academia and industry responded with the development of various inhaled therapeutics, but a plateau in treatment effect seems to have been reached. ${ }^{4}$ Therapeutic procedures that provide durable improvements in COPD patients are rare, but they are a next logical bridge in the treatment of this chronic and progressive disease. However, just as with pharmaceuticals, early safety evaluation of devices must first be undertaken to understand long-term effects prior to moving into larger efficacy clinical trials.

Targeted lung denervation (TLD) is a novel bronchoscopic therapy for COPD that is intended to achieve bronchodilation via ablation of parasympathetic pulmonary nerves entering the lung and running along the outside of the two main bronchi. An earlier study established a reasonable safety profile when treating both lungs in a staged fashion. ${ }^{5}$ The current study was specifically designed to understand the safety profile when completing TLD treatment in both lungs when performed as a single procedure.
Department of Respiratory and Critical Care Medicine, Ludwig-BoltzmannInstitute for COPD and Respiratory Epidemiology, Otto-Wagner-Spital, Sanatoriumstrasse 2, II40 Wien,

Vienna, Austria

Tel +43 69912029642

Email arschang.valipour@wienkav.at
International Journal of COPD 2018:13 2163-2172

Dovepress if in 8

http://dx.doi.org/10.21471COPD.S158748 (c) (1) (5) ( 2018 Valipour et al. This work is published and licensed by Dove Medical Press Limited. The full terms of this license are available at https://www.dovepress.com/terms.php C. hereby accept the Terms. Non-commercial uses of the work are permitted without any further permission from Dove Medical Press Limited, provided the work is properly attributed. For permission for commercial use of this work, please see paragraphs 4.2 and 5 of our Terms (https://www.dovepress.com/terms.php). 
Investigators hypothesized that this would be the preferred way to treat in the future and would result in added safety over treatment staging, mainly due to reduced exposure to anesthesia and reduced risk of exacerbations induced by bronchoscopy. Furthermore, the current study provides 3-year follow-up data in treated patients to provide early information on potential long-term effects of TLD.

\section{Patients and methods}

\section{Study design}

This nonrandomized, prospective single-dose registry study was conducted at four sites in Austria (1 site) and France (3 sites) between September 6, 2012 and May 5, 2015. This design was identical to the previous study ${ }^{5}$ except that TLD therapy was delivered to both lungs during a single procedure (vs staged), a single power (vs two) was investigated, and additional bronchoscopic and computed tomography (CT) assessments at 365 days were conducted to assess safety. Sites did not overlap with the previous published first-in-human study, which helped to strengthen the safety assessment and gain additional user information for device development.

\section{Study participants}

Major entry criteria were identical to the first-in-human study and are listed in Table 1. Follow-up bronchoscopy and CT scans were performed to evaluate the longer-term safety of treatment areas.

\section{Study oversight}

This study was approved by the ethics committee of the City of Vienna (reference: EC 11-251-0112) and the institutional

Table I Protocol's inclusion and exclusion criteria

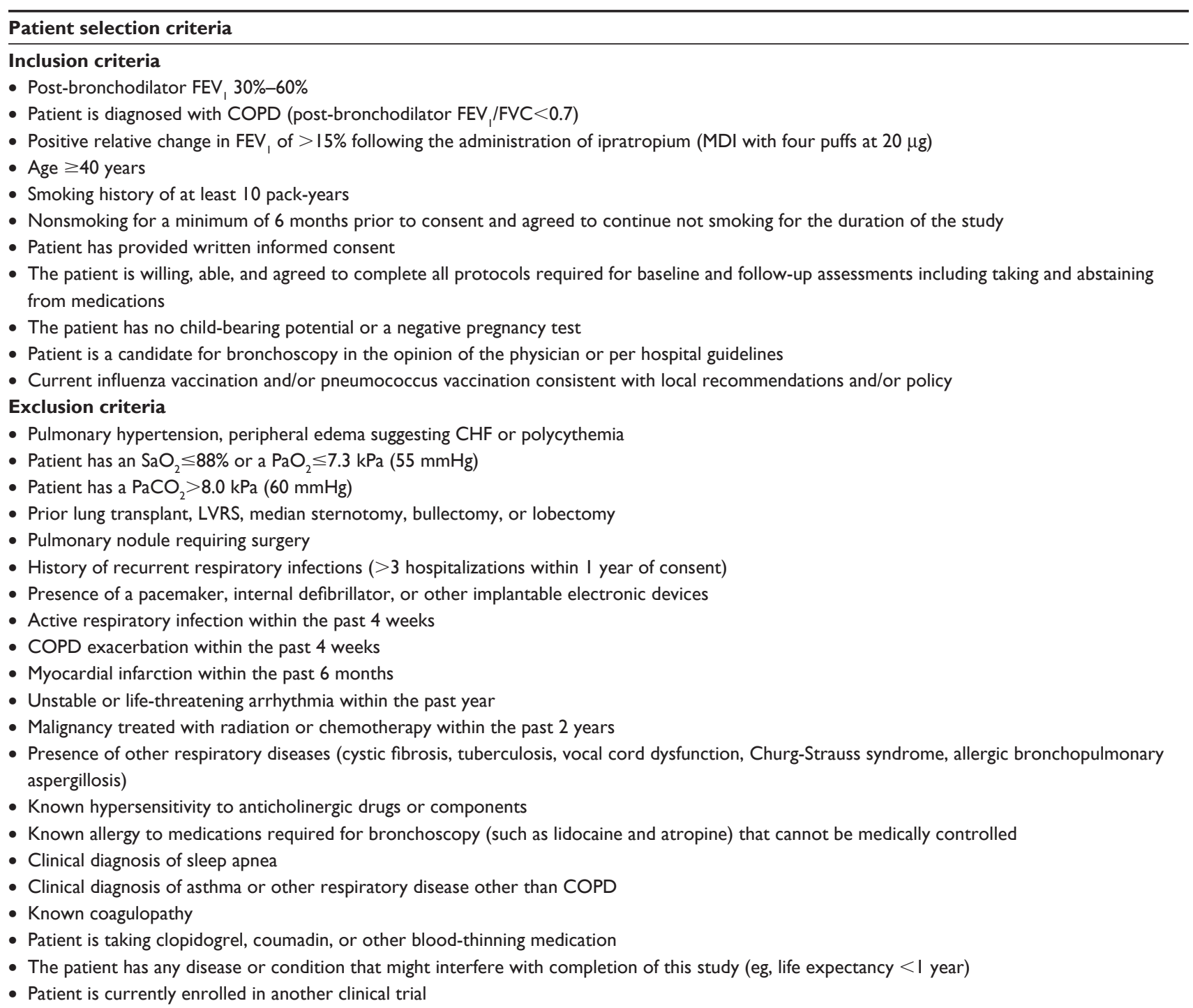

Abbreviations: $\mathrm{CHF}$, congestive heart failure; $\mathrm{FEV}_{1}$, forced expiratory volume in I s; FVC, forced vital capacity; LVRS, lung volume reduction surgery; MDI, metered-dose inhaler; $\mathrm{PaCO}_{2}$, partial pressure of carbon dioxide; $\mathrm{PaO}_{2}$, partial pressure of oxygen; $\mathrm{SaO}_{2}$, saturation of oxygen. 
review board (IRB) of South East V, University Hospital Center Grenoble (France), Committee for patient protection (reference: 2012-A00728-35) and was conducted according to the Declaration of Helsinki (1996), Good Clinical Practice guidelines, and local requirements. Operations and a datamonitoring committee oversaw protocol management and safety for the study. An independent clinical event reviewer adjudicated all reported serious adverse events (SAEs). All participating subjects provided written informed consent.

\section{Procedures}

Analysis included spirometry, body plethysmography, cycle ergometry, 6-min walk test (6MWT), COPD-specific St George's Respiratory Questionnaire (SGRQ, score range $0-100$ with a minimally clinically important difference of $\geq 4$ negative units), ${ }^{6}$ the Clinical SGRQ-C (COPD) (7-day version, score range $0-6$, with an minimally clinically important difference of 0.4 units $),{ }^{7}$ and the common Borg and modified Medical Research Council ${ }^{8}$ scales. All appropriate permissions to use validated questionnaires were obtained by the study sponsor. Cycle ergometry was first conducted as an incremental maximal test to determine the baseline maximum work rate $\left(\mathrm{W}_{\max }\right)$ off drugs and subsequently as an endurance test conducted at a constant work rate of $75 \%$ of the $\mathrm{W}_{\max }{ }^{9}$ The current American Thoracic Society/European Respiratory Society (ATS/ERS) guidelines were followed for pulmonary function test (PFT); ${ }^{10,11}$ however, due to the feasibility nature of the study, no prospective PFT quality oversight program was implemented. ATS/American College of Chest Physicians (ACCPs) and ATS guidelines were followed for cycle ergometry ${ }^{12}$ and the 6MWT, ${ }^{13}$ respectively. Chest CT scan was required to confirm appropriate bronchial anatomy and rule out other pulmonary abnormalities prior to treatment and to evaluate bronchial and peri-bronchial effects following treatment.

Following informed consent, patients underwent "washout" baseline analysis after a washout period of 8 days for long-acting muscarinic antagonists (LAMAs), $24 \mathrm{~h}$ for long-acting beta agonist (LABA), and $12 \mathrm{~h}$ for short-acting beta agonist (SABA) and short-acting muscarinic antagonist (SAMA). Patients were then asked to take tiotropium bromide, and after a minimum of an 8-day run-in period similar analysis was performed on drug trough $24 \mathrm{~h}$ after the last dose of tiotropium to establish "tiotropium trough" baseline values. LABAs were again withheld for $24 \mathrm{~h}$ and SABAs and SAMAs for $12 \mathrm{~h}$ prior to this analysis if taken. Post-treatment, subjects were asked to remain off tiotropium. Similar to the abovementioned information, any COPD medications taken by the patient must have been appropriately washed out (based on half-life of the drug) prior to the follow-up analysis visits. Paper diaries were utilized by the site study coordinators to help manage medications prior to analysis. Detailed medication utilization was not tracked as part of this feasibility study.

All patients underwent early safety evaluation by phone at 3 and 10 days post-procedure and analysis at washout baseline, tiotropium trough baseline, and 30, 90, 180, 270, and 365 days, and then 1.5, 2, 2.5, and 3 years post-treatment if reconsented for longer-term follow-up. Exceptions to the analysis schedule was cycle ergometry that was performed only at washout baseline, 90, 180, and 365 days, and 2 years following treatment; bronchoscopy was performed at treatment and 90 and 365 days post-procedure; CT scan was performed at washout and 365 days after treatment.

\section{TLD}

TLD was delivered via a dual cooled radiofrequency (RF) generator system (Figure 1) and has been previously described. ${ }^{5}$

As RF current is delivered through the airway and surrounding tissues, these tissues are heated and the nerves are ablated. Simultaneous cooling removes heat from the inner surface of the bronchi. The net effect is the targeted tissue ablation at depth with minimal heating and damage of the inner surface of the airway. The goal of targeted ablation is to disrupt motor axons within bronchial nerve branches running along the main bronchi, thereby blocking parasympathetic signaling to the lungs and decreasing neuronal release of acetylcholine (Figure 2).

TLD was performed under general anesthesia via rigid bronchoscopy due to the dimensions of this first-generation catheter. The study was designed to assess the safety of bilateral lung treatment during a single procedure; however, a procedure could be staged per physician discretion. The electrode was placed and activated as prescribed in up to

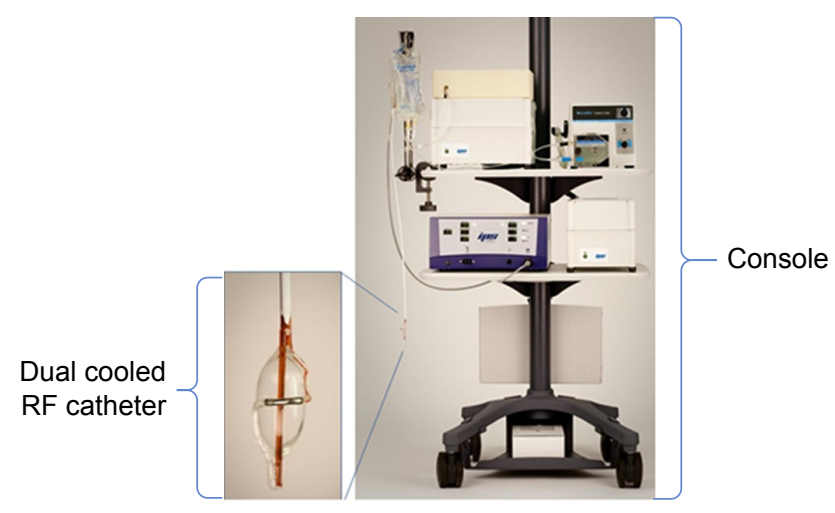

Figure I First generation targeted lung denervation system. Abbreviation: RF, radiofrequency. 


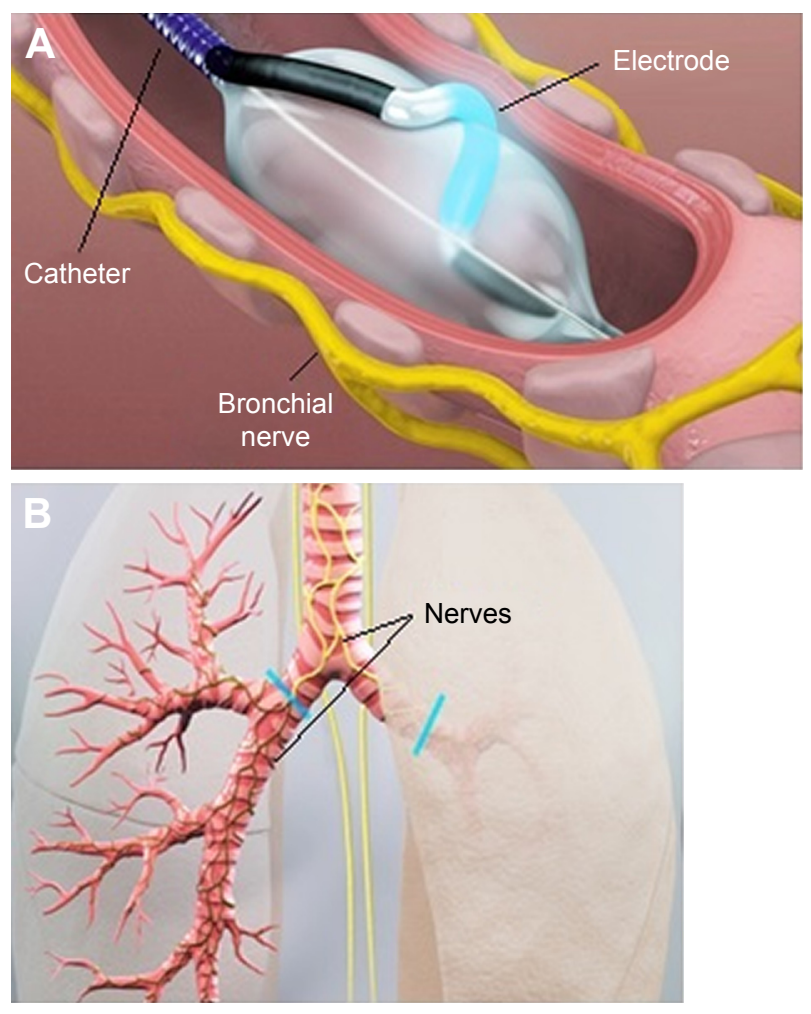

Figure 2 Representative ablation procedure.

Notes: (A) Image of a representative ablation. The catheter is in left bronchus with electrode in the lateral position. Catheter is rotationally repositioned to achieve complete circumferential treatment. Both the catheter and electrode are filled with cooled fluid to protect the airway inner surface during ablation. (B) Blue lines designate the area of circumferential ablation in main bronchi. Attenuation of nerve fibers along the outside of the airway is represented by change in color.

eight rotational positions per bronchus to achieve a complete circumferential treatment. Bronchoscopic and fluoroscopic visualization was used to guide in electrode positioning. Energy-level determination came from extensive preclinical analysis and early safety outcomes from the first-in-human study. ${ }^{5}$ Subjects were asked to stop taking tiotropium after the completion of the procedure.

\section{Study end points}

The primary safety end point of freedom from documented and sustained worsening of COPD directly attributable to the investigational device or procedure to 365 days post-TLD therapy was defined as a decrease in the individual patient's forced expiratory volume in $1 \mathrm{~s}\left(\mathrm{FEV}_{1}\right)$ by any amount at all follow-up time points along with a report of an adverse event that was reported to have a probable or definite relation to the device. Secondary end points included technical feasibility of the device, change in PFTs, exercise capacity assessments, and health-related quality of life. Technical feasibility was defined as the ability to access the target treatment area in the main bronchus and deliver RF energy to the entire circumference of the bronchus at the target treatment sites.

\section{Statistical analyses}

There was no primary study hypothesis with statistical inference for the small registry study. All $p$-values were presented for informational purposes. According to the prespecified analysis plan, continuous data were summarized using mean and SD, or medians and quartiles in the presence of nonnormality. Categorical data were tabulated with counts and percentages. All the available data were summarized with no imputation for missing data. Final analyses were conducted using SAS version 9.3 (SAS Institute Inc., Cary, NC, USA) by an independent statistical group (NAMSA, Minneapolis, $\mathrm{MN}, \mathrm{USA}$ ).

\section{Results}

Baseline characteristics for the 15 patients treated are shown in Table 2. Patient disposition throughout 3 years is shown in Figure 3. Follow-up data beyond 365 days were available for $67 \%(n=10)$ at 2 years and $60 \%(n=9)$ at 3 years. Three patients did not participate in follow-up beyond 1 year and refused or withdrew consent, with one withdrawing due to planned bladder surgeries. Later study exits were due to physician discretion and relocation.

Technical success of TLD treatment was achieved in $93 \%$ of cases, with one patient receiving treatment in seven of eight expected quadrants due to poor balloon contact. No device-related adverse events during the procedure were reported. All 15 patients underwent treatment at an energy level of $15 \mathrm{~W}$. A staged procedure was performed in a total of

Table 2 Baseline characteristics

\begin{tabular}{|c|c|}
\hline Characteristics & $n=15$ \\
\hline Age (years) & $63.20(3.97)$ \\
\hline Male, n (\%) & $7(47)$ \\
\hline \multicolumn{2}{|l|}{ Ethnic origin, $\mathrm{n}(\%)$} \\
\hline White & $15(100)$ \\
\hline History of smoking, n (\%) & $15(100)$ \\
\hline Pack-years & $39.4(6.16)$ \\
\hline Washout pre-bronchodilator $\mathrm{FEV}_{1}(\mathrm{~L})$ & $0.77(0.24)^{*}$ \\
\hline Washout pre-bronchodilator FEV (\%) & $28.6(10.9)^{*}$ \\
\hline Washout pre-bronchodilator FVC (L) & $2.25(0.61)^{*}$ \\
\hline Reversibility peak relative change in $\mathrm{FEV},(\%)$ & $38.01(20.18$ \\
\hline Run-in tiotropium trough, $\mathrm{FEV}_{1}(\mathrm{~L})$ & $1.09(0.22)$ \\
\hline Run-in tiotropium trough, FVC (L) & $2.70(0.73)$ \\
\hline Average diameter: right main bronchus $(\mathrm{mm})^{* *}$ & $14.10(2.74)$ \\
\hline Average diameter: left main bronchus $(\mathrm{mm})^{* *}$ & $13.15(1.69)$ \\
\hline
\end{tabular}

Notes: Data are represented as mean (SD) unless stated otherwise. *Postbronchodilator information not correctly recorded in error. **Measurements by sponsor using Apollo ${ }^{\circledR}$ Software (VIDA Diagnostics, Coralville, IA, USA). Abbreviations: FEV , forced expiratory volume in I s; FVC, forced vital capacity. 


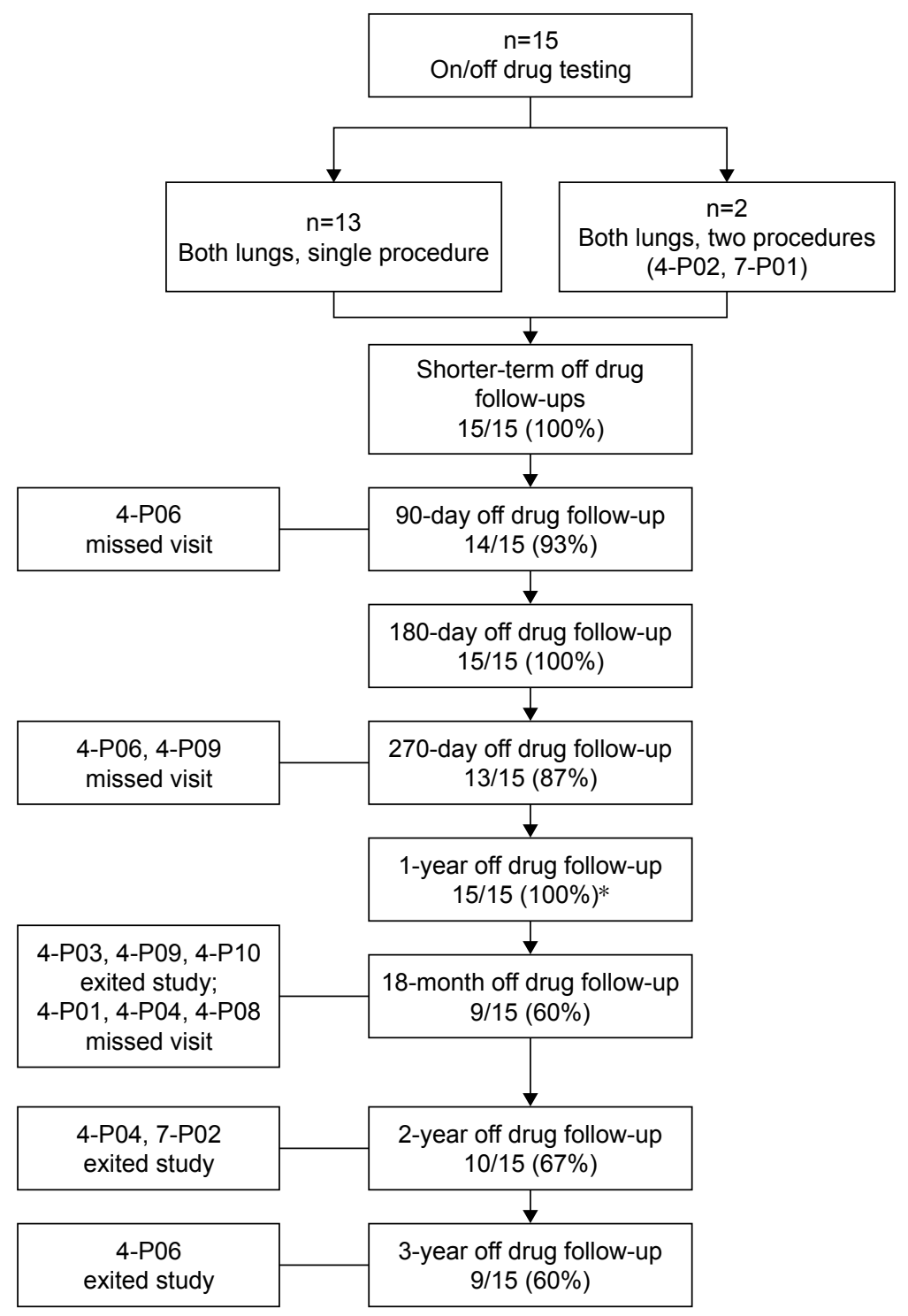

Figure 3 Subject disposition.

Note: *Patients asked to consent for additional follow-up at the I-year visit.

two patients due to the airway size being unexpectedly larger than the balloon available at the time of the initial treatment.

\section{Safety}

The primary safety end point, defined as freedom from documented and sustained worsening of COPD directly attributable to the investigational device or procedure to 365 days post-TLD therapy, was achieved in $100 \%(15 / 15)$ of patients. No significant wall effects (ie, ulcers and narrowing) were observed during this study at either the 90-day or 365-day follow-up bronchoscopy and CT assessments (Figure 4).

No device-related adverse events were reported. No deaths occurred in the entire 3-year follow-up period. A total of 12 SAEs were reported during the follow-up consisting of five COPD exacerbations (occurring at 3 months, 1 year, 1.5 years, and 2 at 2 years), one urinary retention (with difficult Foley catheter placement and sequela of benign prostatic hypertrophy) occurring 30 days post-treatment, one worsening of an underlying arrhythmia 85 days post-treatment, one hemoptysis (negative bronchoscopy and suspected epistaxis), one motorcycle accident at 24 months, one transient ischemic attack between 2 and 3 years post-treatment, and one nonfatal stroke between 2 and 3 years (Table 3 ).

\section{Lung function, exercise capacity, and quality of life}

To understand the impact of TLD alone on efficacy measures, all follow-up tests were performed while washed out of all 


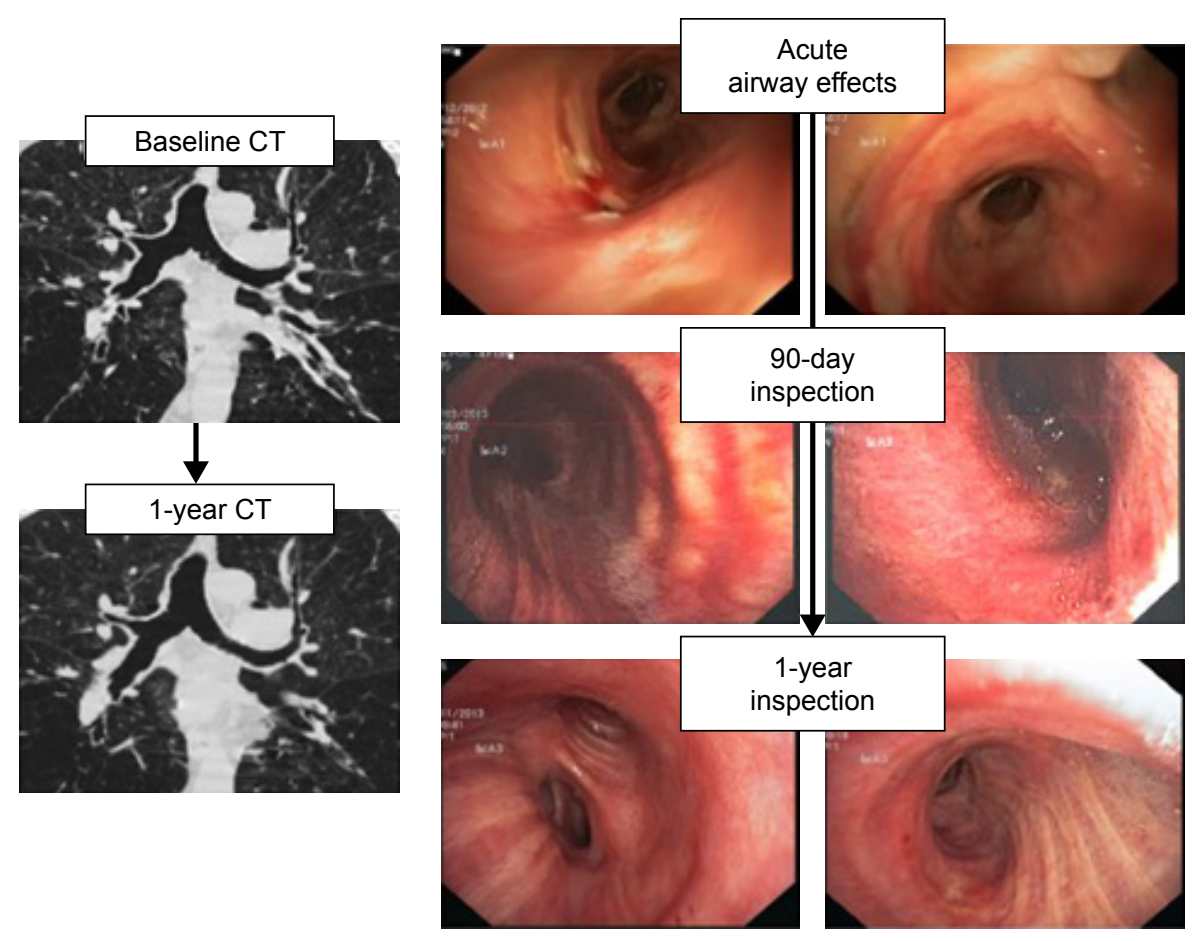

Figure 4 Example of acute and follow-up CT and airway safety inspections. Abbreviation: $\mathrm{CT}$, computed tomography.

Table 3 Summary of adverse events through 3 years

\begin{tabular}{|c|c|c|c|c|}
\hline Adverse event & $\begin{array}{l}\leq 30 \text {-day events } \\
(n=15), n(\%)\end{array}$ & $\begin{array}{l}\geq 30 \text { days to I year } \\
(n=\mid 5), n(\%)\end{array}$ & $\begin{array}{l}I-2 \text { years } \\
(n=10), n(\%)\end{array}$ & $\begin{array}{l}2-3 \text { years } \\
(n=9), n(\%)\end{array}$ \\
\hline \multicolumn{5}{|l|}{ SAEs } \\
\hline COPD exacerbation & & $2(13)$ & $3(30)$ & \\
\hline Heart arrhythmia & & I (7) & & \\
\hline Hemoptysis & & & $I(10)$ & \\
\hline Hypertrophy of prostate & I (7) & & & \\
\hline Motorcycle accident & & & & $\mathrm{I}(\mathrm{II})$ \\
\hline Stroke & & & & $2(22)$ \\
\hline Urinary retention & I (7) & & & \\
\hline \multicolumn{5}{|l|}{ Nonserious adverse events } \\
\hline Common cold & I (7) & & & \\
\hline COPD exacerbation & $2(13)$ & $2(13)$ & II (II0) & $3(33)$ \\
\hline Cough & & I (7) & & \\
\hline Dislodged teeth & I (7) & & & \\
\hline Dysphagia & $2(13)$ & & & \\
\hline Epigastric pain & $2(13)$ & & & \\
\hline Headache & & & & $\mathrm{I}(\mathrm{II})$ \\
\hline Hemoptysis & & I (7) & $\mathrm{I}(\mathrm{I0})$ & \\
\hline Herpes zoster & & & $I(I 0)$ & \\
\hline Hoarseness & & & & $\mathrm{I}(\mathrm{II})$ \\
\hline Hypoxemia & I (7) & & & \\
\hline Lower respiratory infection & & $5(33)$ & I (I0) & \\
\hline Nausea/vomiting & & I (7) & & \\
\hline Paresthesia (left hand) & & & $I(10)$ & \\
\hline Tachycardia & & & & $2(22)$ \\
\hline Tingling in left upper lobe & I (7) & & & \\
\hline Thoracic pain & I (7) & & & \\
\hline Sigmoiditis & & I (7) & & \\
\hline Syncope & & & & $\mathrm{I}(\mathrm{II})$ \\
\hline
\end{tabular}

Abbreviation: SAE, serious adverse event. 
Table 4 Baseline and outcomes at 365 days

\begin{tabular}{|c|c|c|c|c|}
\hline \multirow{2}{*}{$\begin{array}{l}\text { Lung } \\
\text { function } \\
\text { test }\end{array}$} & \multicolumn{4}{|l|}{$n=15$} \\
\hline & \multicolumn{2}{|c|}{ Baseline } & 365 days & $\begin{array}{l}\text { Percent change } \\
\text { from baseline }\end{array}$ \\
\hline $\mathrm{FEV}_{1}(\mathrm{~mL})$ & 765.33 & $3(237.45)$ & I,012.14 (272.99) & $40.29(42.12)^{*}$ \\
\hline \multirow[t]{2}{*}{$\mathrm{FVC}(\mathrm{mL})$} & 2,248 . & $.00(6 \mid 4.05)$ & $2,605.00(634.59)$ & $19.25(24.84)^{*}$ \\
\hline & & Baseline & 365 days & $\begin{array}{l}\text { Absolute change } \\
\text { from baseline }\end{array}$ \\
\hline \multicolumn{2}{|c|}{$\begin{array}{l}\text { Cycle ergometry } \\
\text { (min) }\end{array}$} & $7.36(2.96)$ & $9.81(4.92)$ & $2.68(6.06)$ \\
\hline \multicolumn{2}{|c|}{$\begin{array}{l}\text { Borg scale: post- } \\
\text { cycle dyspnea }\end{array}$} & $5.4(2.35)$ & $4.64(1.21)$ & $-0.82(1.83)$ \\
\hline \multicolumn{2}{|l|}{$\mathrm{mMRC}$} & $2.27(1.03)$ & $1.60(1.06)$ & $-0.67(1.05)$ \\
\hline \multicolumn{2}{|l|}{ 6MWT (m) } & $361.8(125.62)$ & $415.47(112.76)$ & $53.67(74.40)^{*}$ \\
\hline \multicolumn{2}{|c|}{ SGRQ: total score } & $47.95(16.97)$ & $49.37(20.93)$ & $-1.85(20.77)$ \\
\hline \multicolumn{2}{|c|}{ CCQ: total score } & $2.7 \mid(1.17)$ & $2.63(1.4 I)$ & $0.00(1.29)$ \\
\hline
\end{tabular}

Notes: Data are represented as mean (SD) unless stated otherwise. ${ }^{*} p<0.05$ compared with baseline.

Abbreviations: CCQ, Clinical COPD Questionnaire; $\mathrm{FEV}$, forced expiratory volume in I s; FVC, forced vital capacity; mMRC, modified Medical Research Council dyspnea scale; 6MWT, 6-min walk test; SGRQ, St George's Respiratory Questionnaire (COPD specific).

bronchodilators, if taken, as previously described. There were statistically significant improvements in lung function and exercise capacity at 365 days post-TLD treatment (Table 4).

Improvements observed for percent relative change compared with washout baseline of $\mathrm{FEV}_{1}$ were significant at all
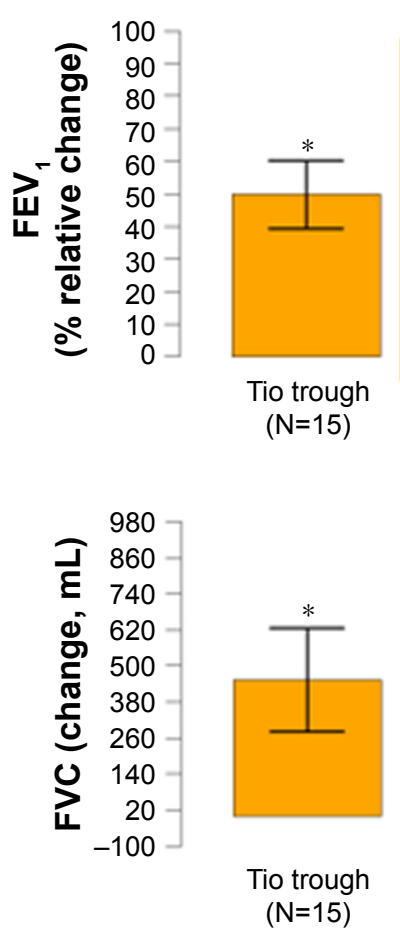
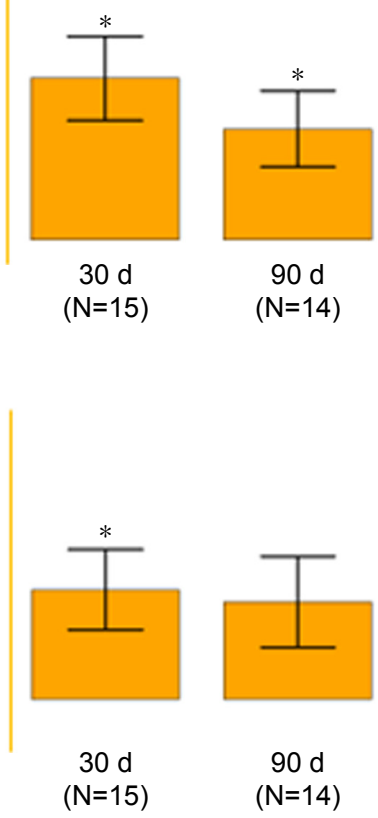
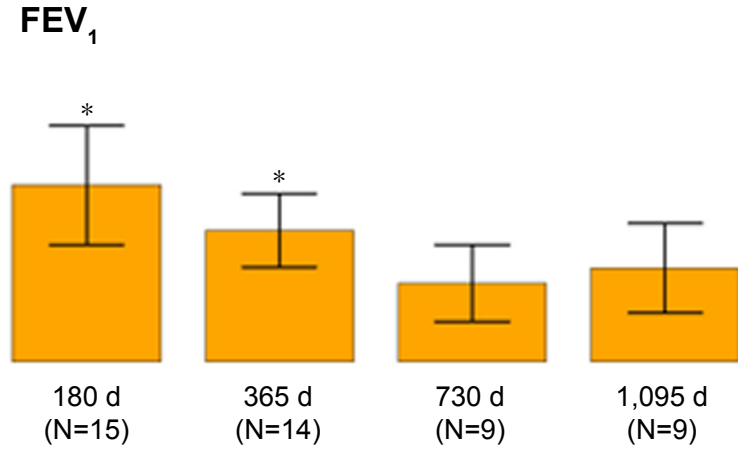

\section{FVC}
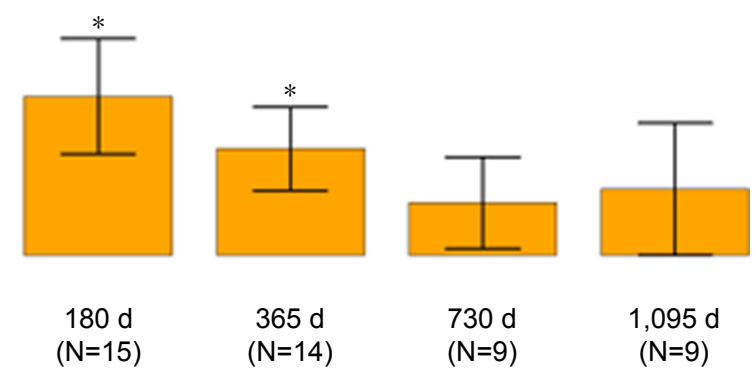

Figure 5 Secondary efficacy end points.

Notes: Yellow line represents timing of TLD procedure. Data are represented as mean. Error bars represent SEM. All measures compared with washout baseline analysis. $*_{p}<0.05$ compared with baseline.

Abbreviations: $\mathrm{FEV}_{1}$, forced expiratory volume in I s; FVC, forced vital capacity; SEM, standard error of the mean; TLD, targeted lung denervation. 
obstruction. ${ }^{16-18}$ TLD is a novel bronchoscopic therapy that, using a minimally invasive approach, ablates the parasympathetic innervation of the lungs and has a similar proposed mechanism of action to surgical denervation, albeit with the potential of lower morbidity and mortality. ${ }^{19}$ TLD therapy ablates airway nerve trunks using predetermined RF energy while minimizing damage to tissues of the main bronchi through the use of a dual cooling method. We have previously reported results from the first-in-human feasibility and safety study of TLD using a sequential, bilateral treatment approach. In that report, TLD was associated with a higher SAE rate of 1.4 events per patient (31 SAEs in 22 patients) up to a follow-up of 1 year. In the current study, patients with similar baseline characteristics experienced an average 3-year SAE rate of 0.26 per patient/year (12 SAEs in 15 patients), which may indicate improved safety by utilizing the bilateral approach and lower delivered energy as well as advancements in overall procedural training over time. ${ }^{5}$ In fact, in the current study, the procedure was consistently modified to more distal electrode placement away from the thin and thermally sensitive main carina, more detailed visual assessment of balloon contact before activation, and a decrease in overall power to $15 \mathrm{~W}$ to further reduce the potential for undesired airway wall effects. In this context, the overall low rate of severe COPD exacerbations during the follow-up period of up to 3 years appears noteworthy. In the absence of a control group, we cannot rule out that this observation is due to a recruitment bias rather than the above-discussed anticholinergic pleiotropic effects, which may influence exacerbation rates similar to pharmacological acetylcholine blockade. Furthermore, given the potential impact of vagotomy on cardiovascular autonomic tone, ${ }^{20}$ it should be noted that there was no evidence of an increased risk of cardiac events associated with the TLD procedure in the current study.

Noteworthy, lung function improvements after TLD therapy at 1 year observed in the current study were of similar magnitude to results from the high-energy cohort (20 W) but higher than the low-energy cohort $(15 \mathrm{~W})$ in our previous study. ${ }^{5}$ The latter observation may be explained by an overall higher peak reversibility response to ipratropium on $\mathrm{FEV}_{1}$ at baseline in the current study cohort (38\%) compared with a reversibility peak relative change in $\mathrm{FEV}_{1}$ between $20 \%$ and $26 \%$ in the previous study. This selection bias may further explain the relatively large magnitude of tiotropium effect during the washout and run-in analysis procedures observed. While the predictive ability of the acute bronchodilator response to long-term inhaled anticholinergic therapy is limited, our observation may indicate a relationship between the response to inhaled short-acting anticholinergic therapy and effects of permanent vagal denervation using TLD therapy. We should acknowledge, however, that the absence of acute bronchodilator response at one occasion may not preclude the demonstration of bronchodilator response on another occasion, ${ }^{21}$ thus limiting the overall usefulness of this criterion for future patient selection for TLD therapy. Another potential explanation for the differences in outcomes between the $15 \mathrm{~W}$ cohorts is the lower rates of SAEs observed in the current manuscript compared with our previous work, which may have contributed to an overall better treatment response in the absence of clinical events compromising potential benefits of TLD.

The current study furthermore demonstrated sustained effects of TLD therapy on $\mathrm{FEV}_{1}$ and FVC up to 3 years compared with baseline. In addition to the bronchodilator effect that is expected by reducing the release of acetylcholine from the parasympathetic nerves, a previous inflammatory marker study has also provided evidence of potentially inhibiting inflammation and mucus gene expression with TLD therapy. ${ }^{22}$ This finding is consistent with other studies that indicate anti-inflammatory effects of inhaled anticholinergic therapy. ${ }^{23,24}$

While the improvements in lung function were in part accompanied by benefits in exercise capacity, they did not translate into consistent benefits of health-related quality of life in this study. There are a number of potential explanations for this observation as well as other limitations to this report. First, the small sample size likely leads to variability across the time points assessed and not all patients continued follow-up beyond 365 days when the study was extended. Second, it has to be acknowledged that there is a rather modest relationship between treatment-related improvements in $\mathrm{FEV}_{1}$ and health-related quality of life. ${ }^{25}$ On the other hand, we have to acknowledge that in the absence of a control group undergoing a sham treatment and the lack of direct measurements of therapeutic efficacy of TLD, such as histological proof of denervation in vivo, improvements in lung function and exercise capacity observed in the current study may have been an intervention effect, rather than a result of the intended mechanism of action. Given the magnitude of response with respect to the $\mathrm{FEV}_{1}$ demonstrated in this study and a strict inhaler washout procedure prior to lung function measurements, however, there is a high likelihood of an independent treatment effect.

With long-term safety of TLD being established between two studies now, focus will be on optimizing the energy dose, 
further refining the procedure, studying potentially additive effects of TLD on top of LAMA treatment, and conducting careful patient phenotyping analysis to identify those patients most likely to benefit from this novel therapy. Since study completion, the manufacturer has made significant device enhancements which allow replacement of rigid bronchoscopy with flexible endoscopy and is currently conducting a randomized, sham control dose and patient selection optimization study.

\section{Conclusion}

This intervention study adds to the early body of evidence confirming the feasibility and safety of TLD in patients with symptomatic moderate-to-severe COPD.

\section{Acknowledgments}

We would like to thank the investigators, coordinators, and patients who participated in this study and acknowledge the late Chris T Bollinger (Stellenbosch University, Cape Town, South Africa) who assisted with study design. This study was funded by Nuvaira, Inc. (Minneapolis, MN, USA). Part of this study was presented in abstract form at the ERS Congress 2015 (Amsterdam, the Netherlands). The clinical trial registration number is ClinicalTrials.gov, NCT01716598.

\section{Author contributions}

Data analysis and interpretation, manuscript drafting, revisions, and approval: AV. Data collection and manuscript revisions: SA, MJ, KB, and MV. Data analysis and interpretation and revisions: CP, RK, and GD. Study design, data analysis and interpretation, manuscript drafting, revisions, and approval: DJS and MM. AV is the guarantor of the content of this manuscript, having full access to the data, and takes responsibility for the integrity of the analysis. All authors contributed toward data analysis, drafting and revising the paper and agree to be accountable for all aspects of the work.

\section{Disclosure}

AV received consultancy fees from Astra Zeneca, Boehringer Ingelheim, Chiesi, GSK, Novartis, Nuvaira, Inc., Olympus, PneumRx, PulmonX, and Uptake Medical or treated patients with the device developed by them. SA received none. CP treated patients with the device developed by Nuvaira, Inc., PneumRx, and PulmonX. MJ received none. RK received consultancy fees from Astra Zeneca, Boehringer Ingelheim, GSK, Novartis, Nuvaira, Inc., PneumRx, and PulmonX or treated patients with the device developed by them. DJS received consultancy fees from Aeris Therapeutic, Boston Scientific, Broncus Technologies, CSA medical, Nuvaira, Inc., Olympus, Portaero, PulmonX, and PneumRx/ BTG or treated patients with the device developed by them. $\mathrm{MM}$ is a founder and stockholder of Nuvaira, Inc. and the inventor of the device used in this study. KB, GD, and MV received none. The authors report no other conflicts of interest in this work.

\section{References}

1. Celli BR, Decramer M, Wedzicha JA, et al; ATS/ERS Task Force for COPD Research. ATS/ERS research questions in COPD. Eur Respir J. 2015;45:879-905.

2. Global Initiative for Chronic Obstructive Lung Disease [homepage on the Internet]. Global Strategy for the Diagnosis, Management and Prevention of COPD; 2017. Available from: http://www.goldcopd.org. Accessed April 13, 2018.

3. GBD 2015 Chronic Respiratory Disease Collaborators. Global, regional, and national deaths, prevalence, disability-adjusted life years, and years lived with disability for chronic obstructive pulmonary disease and asthma, 1990-2015: a systematic analysis. Lancet Respir Med. 2015;5: 691-706.

4. Cazzola M, Page C, Calzetta L. Pharmacology and therapeutics of bronchodilators. Pharmacol Rev. 2012;64:450-504.

5. Slebos D, Klooster K, Koegelenbarg C, et al. Targeted lung denervation for moderate to severe COPD: a pilot study. Thorax. 2015;70: 411-419.

6. Meguro M, Barley E, Spencer S, Jones P. Development and validation of an improved, COPD-specific version of the St George Respiratory Questionnaire. Chest. 2007;132:456-463.

7. van der Molen T, Willemse B, Schokker S, ten Hacken N, Postma D, Juniper E. Development, validity and responsiveness of the Clinical COPD Questionnaire. Health Qual Life Outcomes. 2003;1:13.

8. Bestall JC, Paul EA, Garrod R, Garnham R, Jones PW, Wedzicha JA. Usefulness of the Medical Research Council (MRC) dyspnoea scale as a measure of disability in patients with chronic obstructive pulmonary disease. Thorax. 1999;54:581-586.

9. Maltais F, Hamilton A, Marciniuk D, et al. Improvements in symptomlimited exercise performance over $8 \mathrm{~h}$ with once-daily tiotropium in patients with COPD. Chest. 2005;128:1168-1178.

10. Miller M, Hankinson J, Brusasco V, et al. ATS/ERS Task Force: standardization of lung function testing: standardization of spirometry. Eur Respir J. 2005;26:319-338.

11. Wanger J, Clausen J, Coates A, et al. ATS/ERS Task Force: standardisation of lung function testing; standardisation of the measurement of lung volumes. Eur Respir J. 2005;26:511-522.

12. Weisman I, Marciniuk D, Martinex F, et al. ATS/ACCP statement on cardiopulmonary exercise testing. Am J Respir Crit Car Med. 2003; 167:211-277.

13. ATS Committee on Proficiency Standards for Clinical Pulmonary Function Laboratories. ATS statement: guidelines for the six-minute walk test. Am J Respir Crit Car Med. 2002;166:111-117.

14. Kistemaker L, Oenema T, Meurs H, Gossens R. Regulation of airway inflammation and remodel by muscarinic receptors: perspectives of anticholinergic therapy in asthma and COPD. Life Sci. 2012;91: $1126-1133$.

15. Powrie D, Wilkinson T, Donaldson G, et al. Effect of tiotropium on sputum and serum inflammatory markers and exacerbations in COPD. Eur Respir J. 2007;30:427-478.

16. Bradley G, Hale T, Pimble H, Rolandson R, Noble M. Effect of vagotomy on the breathing pattern and exercise ability in emphysematous patients. Clin Sci. 1982;62:311-319. 
17. Gay M, Rienhoff W. Further observations on the treatment of intractable bronchial asthma by bilateral resection of the pulmonary plexus. J Allergy. 1942;13:626-631.

18. Dimitrov-Szokodi D, Husveti A, Balogh G. Lung denervation in the therapy of intractable bronchial asthma. J Thoracic Surg. 1957;33: 166-184.

19. Belmonte K. Cholinergic pathways in the lungs and anticholinergic therapy for chronic obstructive pulmonary disease. Proc Am Thorac Soc. 2005;2:297-304.

20. Chang HY, Lo LW, Chou YH, et al. Effect of vagotomy on the activity of cardiac autonomic ganglia: insight from left atrial high density frequency mapping. Int J Cardiol. 2016;220:435-439.

21. Hanania N, Bartolome C, Donohue J, Martin U. Bronchodilator reversibility in COPD. Chest. 2011;140:1055-1063.
22. Kistemaker L, Slebos D, Meurs H, Kerstjens H, Gossens R. Antiinflammatory effect of targeted lung denervation in patients with COPD. Eur Respir J. 2015;46:1489-1492.

23. Vacca G, Randerath W, Gillissen A. Inhibition of granulocyte migration by tiotropium bromide. Respir Res. 2011;12:24.

24. Buhling F, Lieder N, Kuhlmann U, Waldburg N, Welte T. Tiotropium suppresses acetylcholine-induced release of chemotactic mediators in vitro. Respir Med. 2007;101:2386-2394.

25. Jones P, Donohue J, Nedelman J, Pascoe S, Pinault G, Lassen C. Correlating changes in lung function with patient outcomes in chronic obstructive pulmonary disease: a pooled analysis. Respir Res. 2011;12:161.

\section{Publish your work in this journal}

The International Journal of COPD is an international, peer-reviewed journal of therapeutics and pharmacology focusing on concise rapid reporting of clinical studies and reviews in COPD. Special focus is given to the pathophysiological processes underlying the disease, intervention programs, patient focused education, and self management protocols.

\section{Dovepress}

This journal is indexed on PubMed Central, MedLine and CAS. The manuscript management system is completely online and includes a very quick and fair peer-review system, which is all easy to use. Visit $\mathrm{http}: / / \mathrm{www}$.dovepress.com/testimonials.php to read real quotes from published authors. 